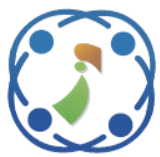

\title{
Performance Analysis and Fault Classification in a Large Electric Motor Using Vibration Assessment Technique
}

\author{
Boonlert Suechoey ${ }^{1 *} \quad$ Somsak Siriporananon $^{1} \quad$ Pana Chupun $^{1}$ \\ Churirat Boonkhun $^{2} \quad$ Chai Chompooinwai ${ }^{2 *}$ \\ ${ }^{I}$ Electrical Engineering Department, Graduate Study, Faculty of Engineering, \\ Southeast Asia University (SAU), Bangkok, Thailand \\ ${ }^{2}$ Faculty of Engineering, King Mongkut's Institute of Technology Ladkrabang (KMITL), Bangkok, Thailand \\ *Corresponding author’s Email: tdlert@ hotmail.com, chaichompoo@gmail.com
}

\begin{abstract}
This research paper presents an analysis of electric motors performance by the assessment of vibration characteristics caused by bearing faults, housing bearing looseness and rotor unbalance. In this study, an analysis of fault that occurred in electric motor has followed ISO 10816-3 Standard. Bring the used electric motors for testing and measuring the vibration of the electric motors by using the Spectrum Analysis \& Field Balancing Analyzer model ADASH A440-VA4 Pro. The vibration results of $22 \mathrm{~kW}, 55 \mathrm{~kW}$ and $75 \mathrm{~kW}$ motor imply the malfunction of bearing faults, housing bearing looseness, and rotor unbalance. The results obtained from the analysis will be used as references and guidelines for predictions of faults in the electric motors, including maintenance scheduling of electric motors.
\end{abstract}

Keywords: Electric motor performances, Mechanical vibrations, Bearing faults.

\section{Introduction}

Typically, electric motors are used in various industrial applications to convert electrical power to mechanical power in the production line. When the performance of electric motors degrades due to long term operation or internal damages, especially a large scale motor, it will directly affect to the production line efficiency and resulting in loss of revenue. Therefore, condition monitoring of the electric motor performance is of great importance tool for fault prediction in the electric motor for a proper repairing or scheduling maintenance of the motor [1-2]. Defects and faults of the electric motors may be caused by bearing faults, housing bearing looseness, rotor unbalance and etc. [3-5].

There are many research works on motor performance and efficiency. The authors in ]6[ present vibration analysis technique to detect faults in small single phase motors. They reveal the continuous measured parameter of machines in order to monitor the time domain of an electromagnetic torque and voltage across capacitors. Moreover, researchers from 17] propose the technique of motor conditioning monitoring by measuring a $1 \mathrm{HP}$ motor vibration. The key idea is to find the difference between equivalent energy consumption in each month. If motor consumed more energy usage than the previous record, it implies that fault may be applied in that monitored unit.

Although many research works have done about motor performance monitoring. However, no one has focused on the performance analysis and fault classification of large scale motors. Therefore, this research has proposed a new technique for electric motors performance analysis by an assessment of vibration characteristics caused by bearing faults, housing bearing looseness and rotor unbalance. This new technique is focus on determining the amplitude of the vibration frequency according to the ISO 10816-3 Standard. 


\section{Theory}

\subsection{Bearing faults}

A ball bearing consists of an inner or outer raceway and balls separated by a cage under normal working conditions, which may cause the defects or damages by rolling fatigue. Apart from the ball bearing defects, induction motor bearing fault may occur, resulting in the raceway defects. Issue of bearing fracture may lead to noises and vibration on motor. Another problem of insufficient lubrication or misalignment can also worsen the motor operation performance.

Typically, there are four types of bearing defect:

- Outer raceway defects

- Inner raceway defects

- Ball defects

- $\quad$ Cage defects

Area fits within the space allowed.

Vibration measurement [8] of ball bearing distinguishes problems in lubrication, dust particles, bearing installation, and fatigue in the ball bearing based on the principle of "Acceleration Enveloping, $\mathrm{gE}$ " that $\mathrm{gE}$ values indicate the performance of bearing condition as shown in Fig. 3 .

\subsection{Housing bearing looseness}

Housing bearing is equipment to support a rotor shaft which contains the bearing to lessen friction. When the housing bearing looseness occurs, it generates vibrations at a frequency of $1 \times R P S$ and the harmonics will dominate at 1xRPS to 10xRPS. In

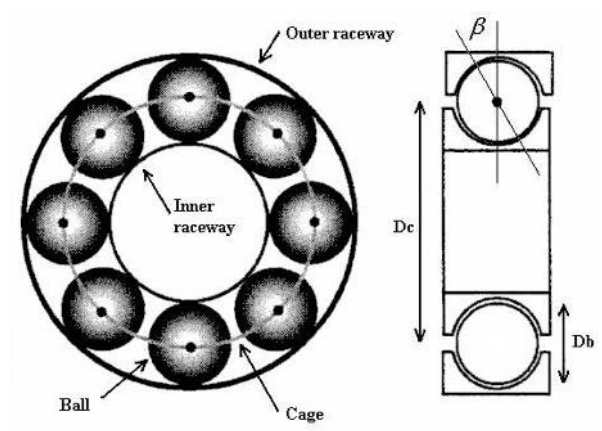

Figure. 1 Ball bearing structure

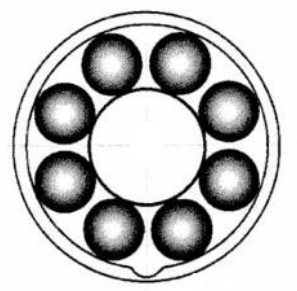

(a)

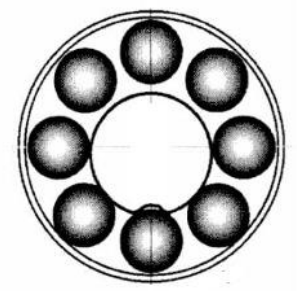

(b)
Figure. 2 Raceway defects: (a) outer and (b) inner

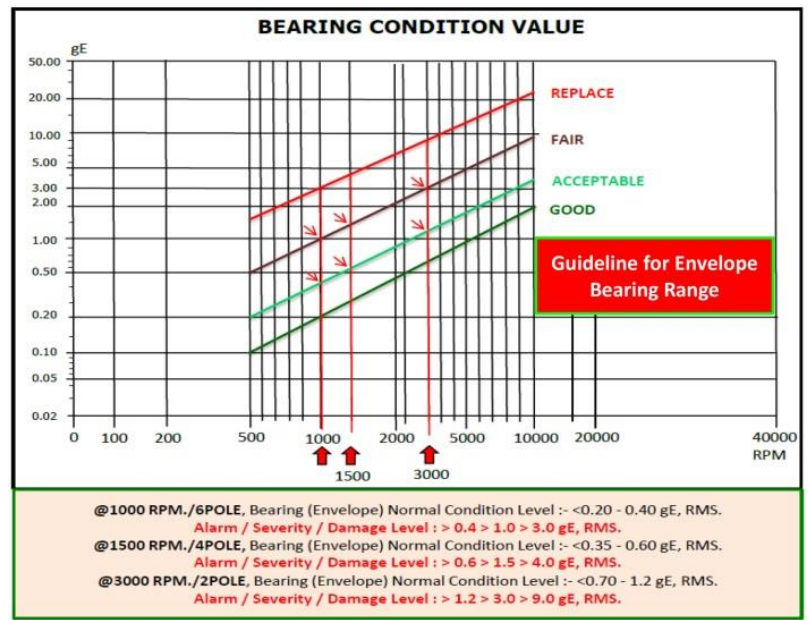

Figure. 3 Guideline for envelope bearing range (gE) [9]

some cases, sub-harmonics occur at $1 / 2$ RPS, as shown in Fig. 4.

\subsection{Rotor unbalance}

Unbalance in the system and rotation cause the vibrations as shown in Fig. 5. Typically, unbalance is divided into 2 following types: 1) Static unbalance occurs when the inertia axis is shift out of alignment center and parallel to the rotating axis, which may be caused by the C.G. point with misalignment. 2) Dynamic unbalance occurs when the system has more than one unbalanced plane, which may be equal or unequal in angles and amplitudes. These result in the inertia axis unparalleled to the rotating axis and couple unbalance may occur while the rotating part has an elongated axial length compared to their diameters. The rotor unbalance usually presents at a frequency of 1xRPS as illustrated in Fig. 4.

\subsection{Analysis of machine vibration}

The ISO 10816-3 International Standard is used for evaluation of the mechanical vibration. In the case of the abnormally high level of vibration occurs in machinery, it indicates the measurement of vibration conditions with reference to the ISO 108163 Standard as illustrated in Fig. 6.

\section{Design and operating procedure}

The tested motors are set up to measure their vibration by using the Spectrum Analysis \& Field Balancing Analyzer model ADASH A440-VA4 Pro. The vibration measurement was conducted to classify types of damage caused by bearing faults, housing bearing looseness, or rotor unbalances [12]. The damage analysis and maintenance procedure are followed Fig. 7. 


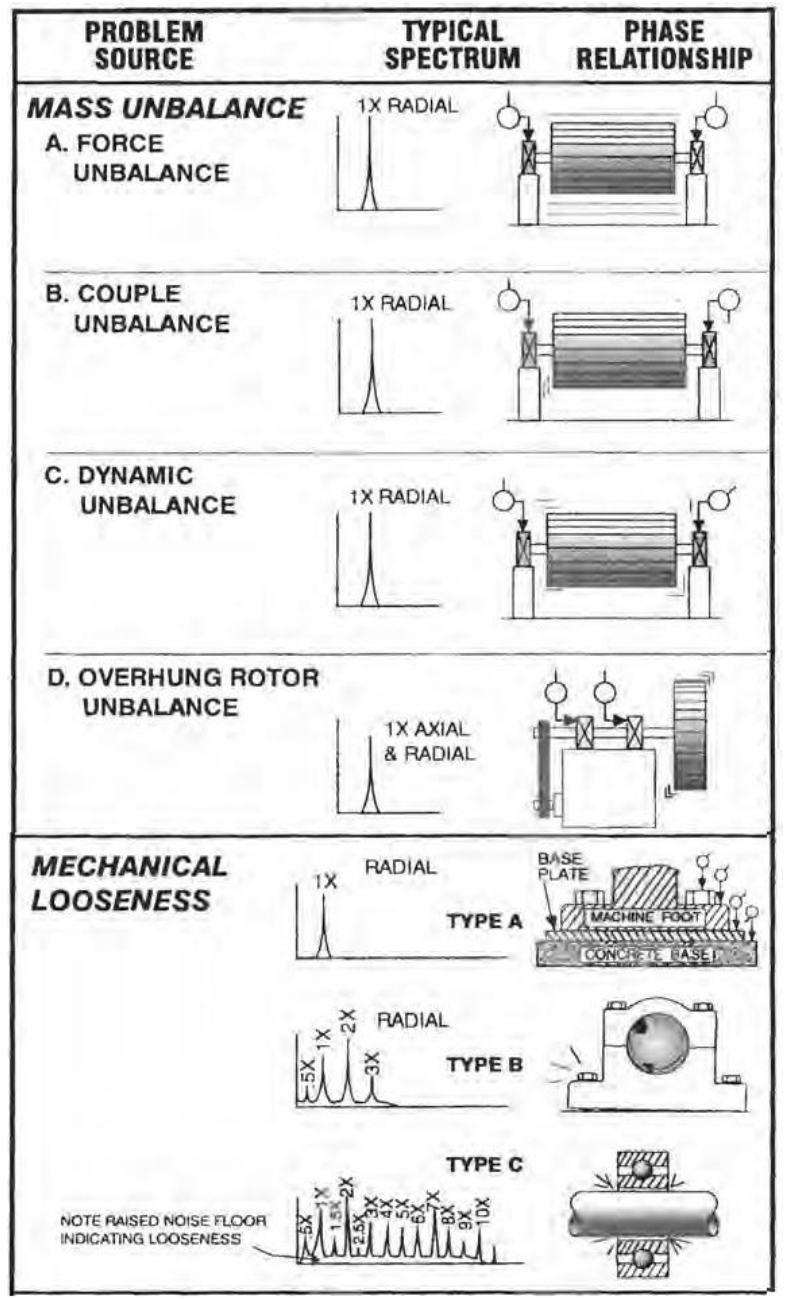

Figure. 4 Illustrated vibration diagnosis at different points [10]

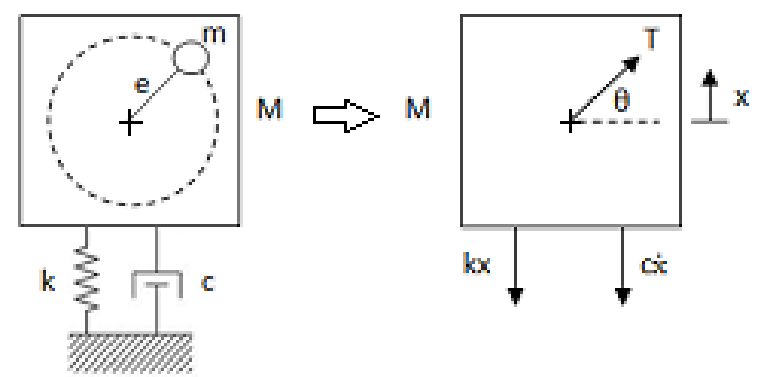

Figure. 5 System unbalanced

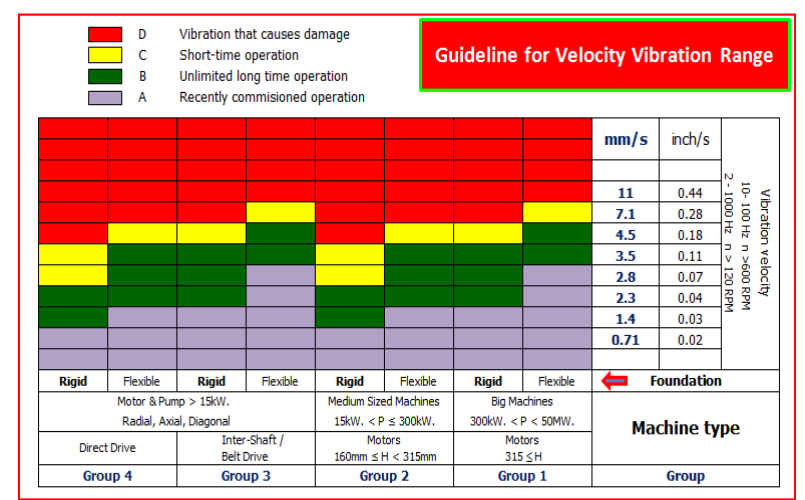

Figure. 6 International standard for vibration analysis [11]

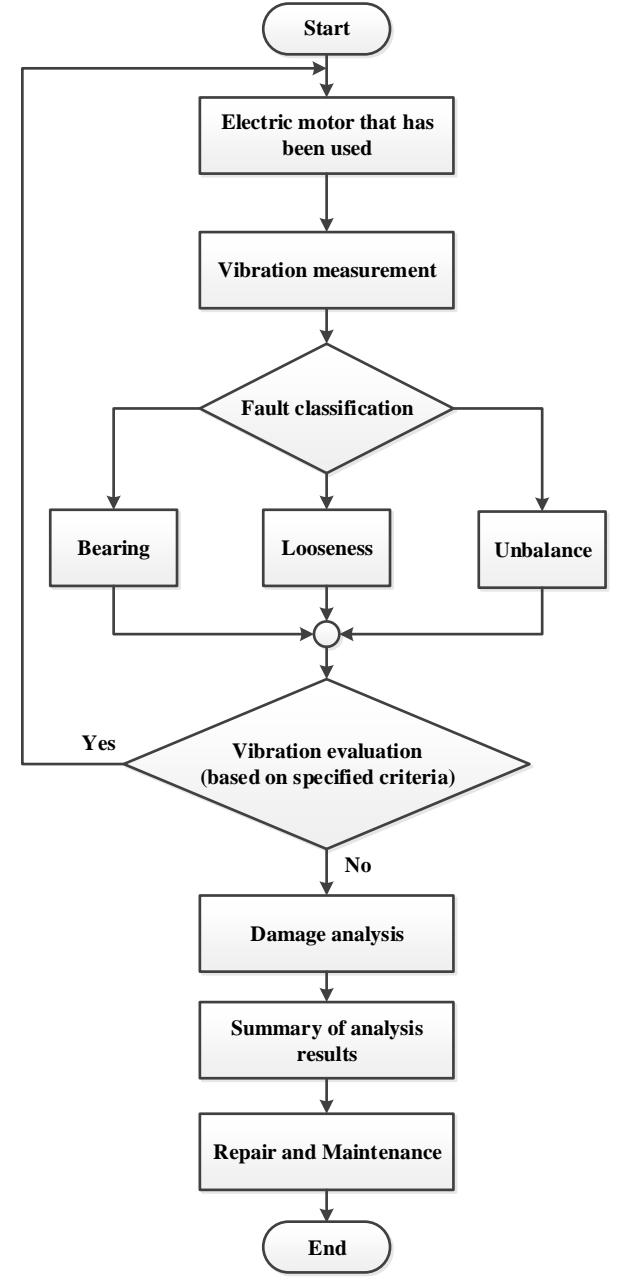

Figure. 7 Operating procedures

\section{Testing procedures and results}

\subsection{Testing processes [13-15]}

The testing processes are followed.

1) Enter the voltages for the electric motor to achieve the RPS as specified by the motor nameplate.

2) Measure the electric motor vibrations and $\mathrm{gE}$ values.

3) Damage analysis.

Perform repair and maintenance and repeat the processes 1 to 3 respectively.

\subsection{Testing results}

1) Experimental results of the $22 \mathrm{~kW}$ motor with 1,465 rpm as shown in Fig. 8-11 and Tables 1-2.

From Table 1, before maintenance, vibration values occur at frequencies: 1xRPS, 2xRPS, and $3 \times$ RPS indicating harmonic values and indicating bearing looseness as shown in Fig. 4. After maintenance, the values at the frequencies: 1xRPS, 2xRPS and 3xRPS decreased. 


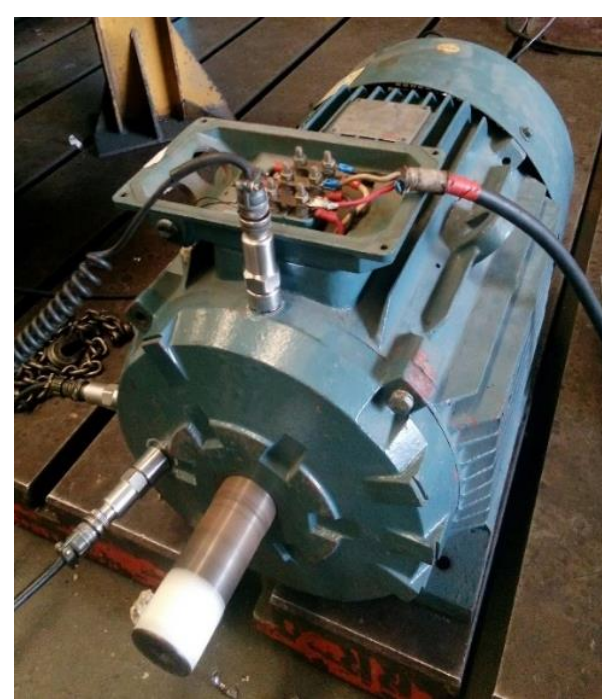

(a)

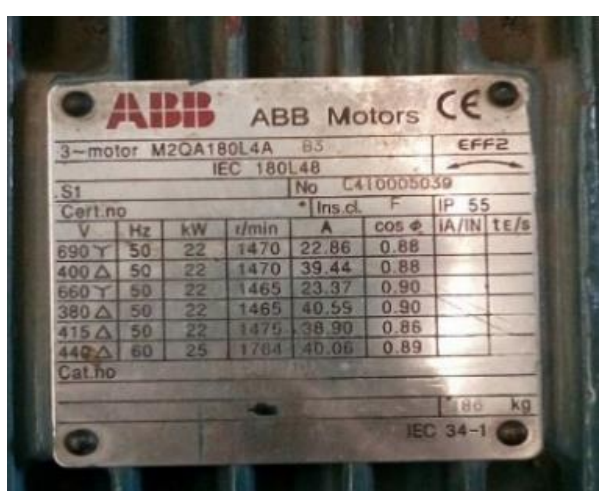

(b)

Figure. $822 \mathrm{~kW}$ motor with 1,465 rpm in the experiment: (a) tested motor and (b) motor's nameplate

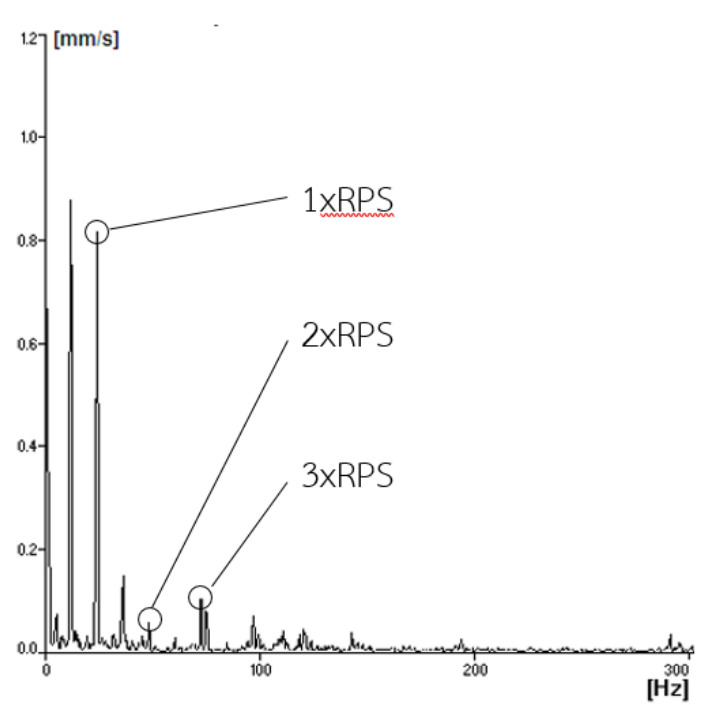

(a)

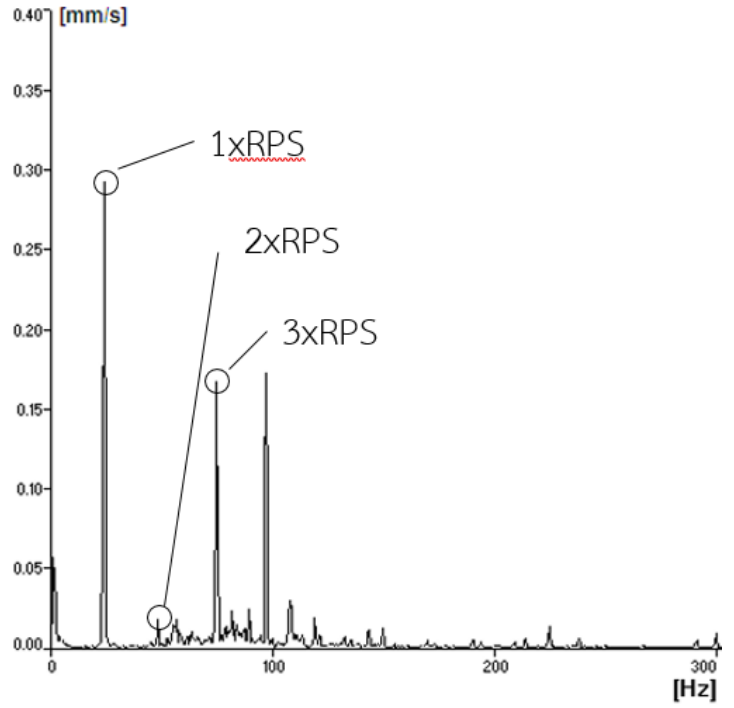

(b)

Figure. 9 Vibration results from 22kW motor: (a) before maintenance and (b) after maintenance

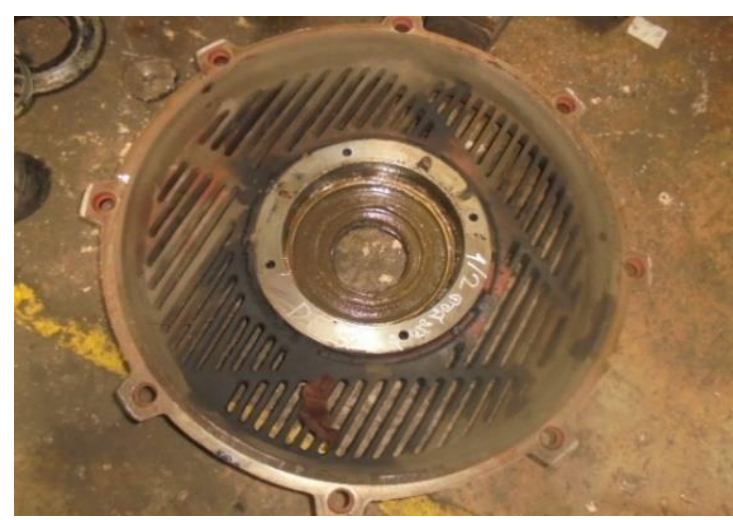

(a)

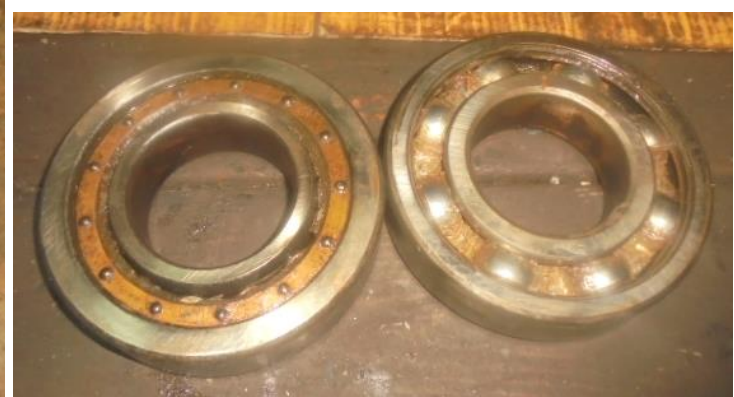

(b)

Figure. 10 Parts of $22 \mathrm{~kW}$ motor before maintenance: (a) bearing housing and (b) bearing 


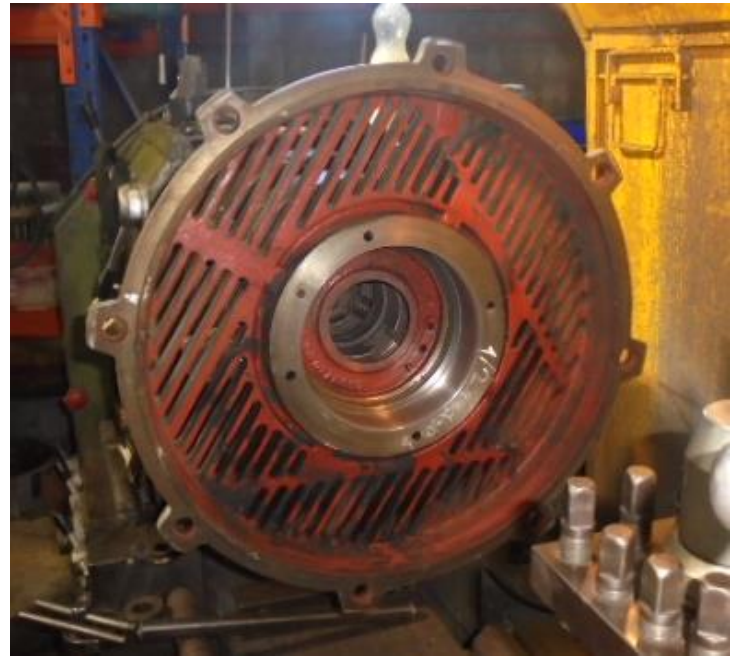

(a)

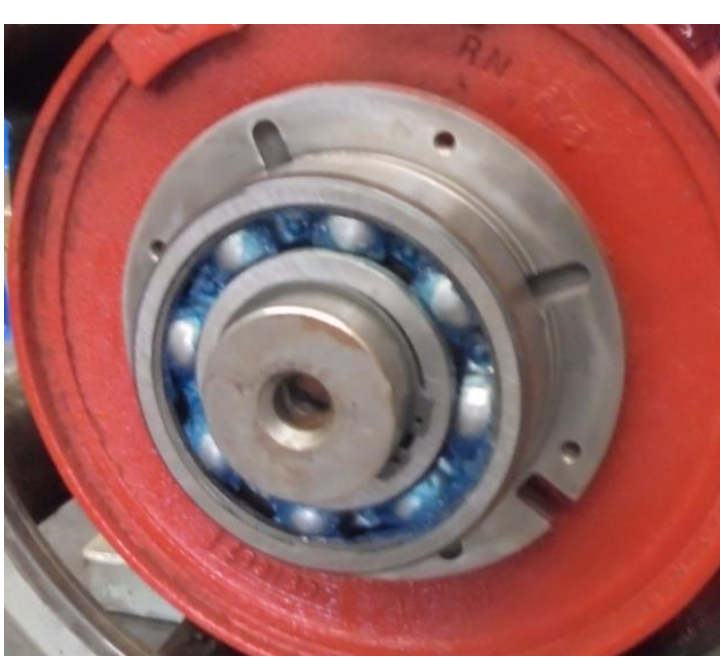

(b)

Figure. 11 Parts of 22kW motor after maintenance: (a) bearing housing and (b) bearing

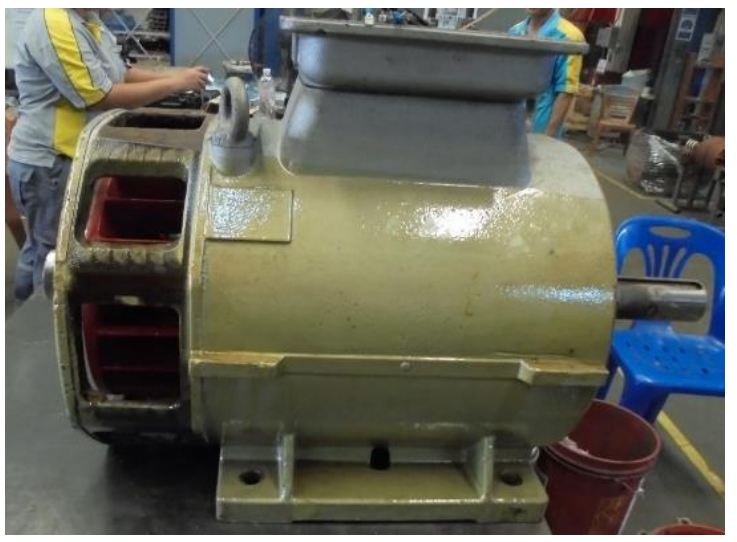

(a)

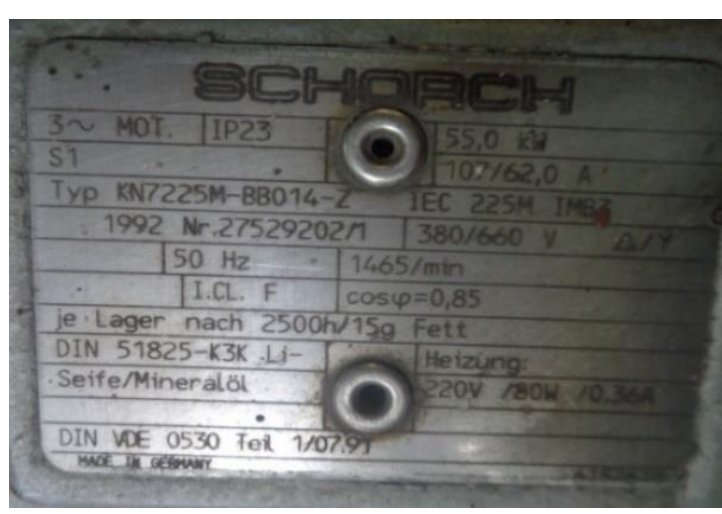

(b)

Figure. $1255 \mathrm{~kW}$ motor with 1,465 rpm in the experiment: (a) tested motor and (b) motor's nameplate

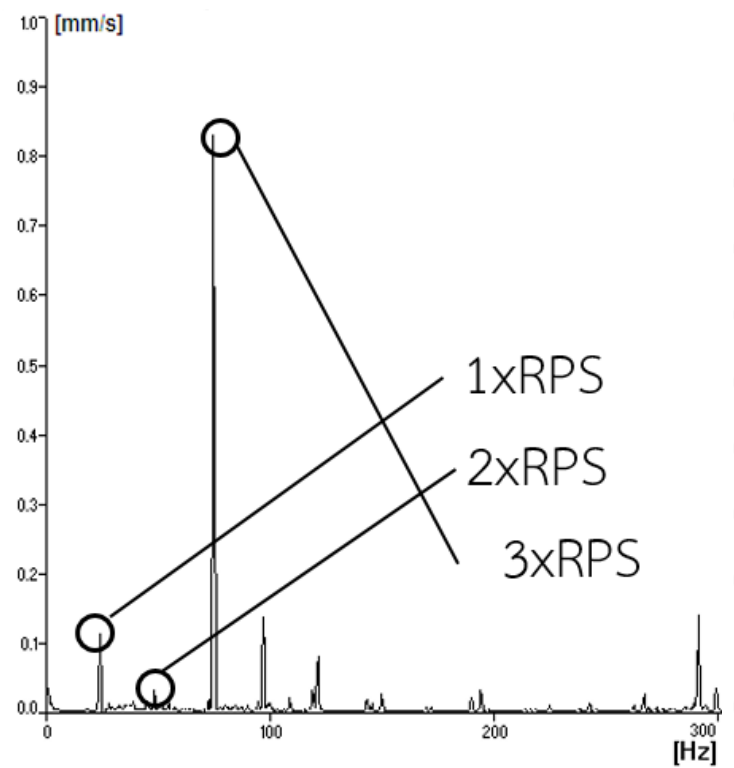

(a)

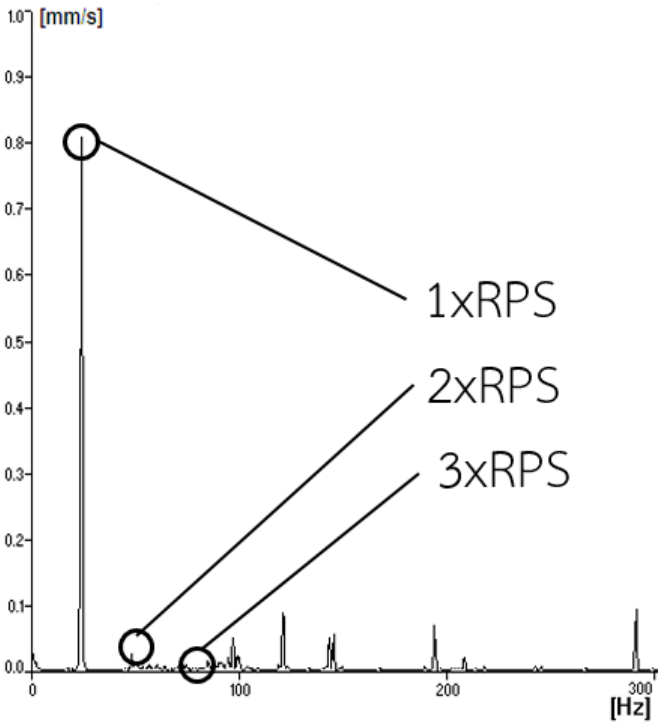

(b)

Figure. 13 Vibration results from 55kW motor: (a) before maintenance and (b) after maintenance 
Table 1. Vibration measurement result of $22 \mathrm{~kW}$ motor

\begin{tabular}{|l|l|l|l|l|l|l|}
\hline \multirow{2}{*}{$\begin{array}{l}\text { Hori } \\
\text { zontal }\end{array}$} & \multicolumn{2}{|c|}{$\begin{array}{c}\text { 1xRPS } \\
\text { (mm/S) }\end{array}$} & \multicolumn{2}{c|}{$\begin{array}{c}\text { 2xRPS } \\
\text { (mm/s) }\end{array}$} & \multicolumn{2}{c|}{$\begin{array}{c}\text { 3xRPS } \\
\text { (mm/S) }\end{array}$} \\
\cline { 2 - 7 } & Before & After & Before & After & Before & After \\
\hline $\begin{array}{l}\text { Fron } \\
\text { t }\end{array}$ & 0.82 & 0.29 & 0.08 & 0.02 & 0.12 & 0.16 \\
\hline Rear & 0.28 & 0.25 & 0.06 & 0.04 & 0.11 & 0.11 \\
\hline
\end{tabular}

Table 2. Defects result from bearing faults of $22 \mathrm{~kW}$

\begin{tabular}{|l|c|l|}
\multicolumn{1}{|c}{ Condition } & gE & Remarks \\
\hline Before maintenance & 2.57 & Good performance \\
After maintenance & 0.19 & less than 0.6 gE \\
\hline
\end{tabular}

From Table 2, before maintenance, it found a high $\mathrm{gE}$ value, in which indicates the defects caused by the bearing as shown in Fig. 3. After replacing the bearing, the $\mathrm{gE}$ value is decreased and the loose bearing disappears.

2) Results of the experiment on the $55 \mathrm{~kW}$ motor with 1,465 rpm as shown in Figs. 12-15 and Tables 3-4.

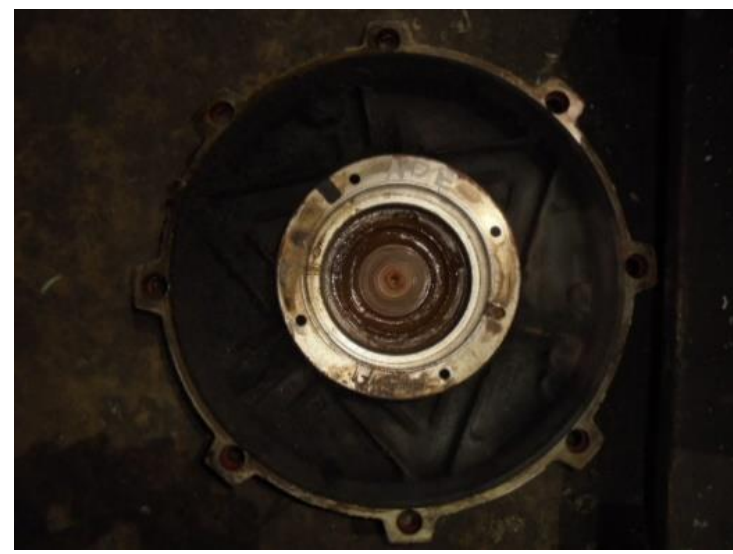

(a)

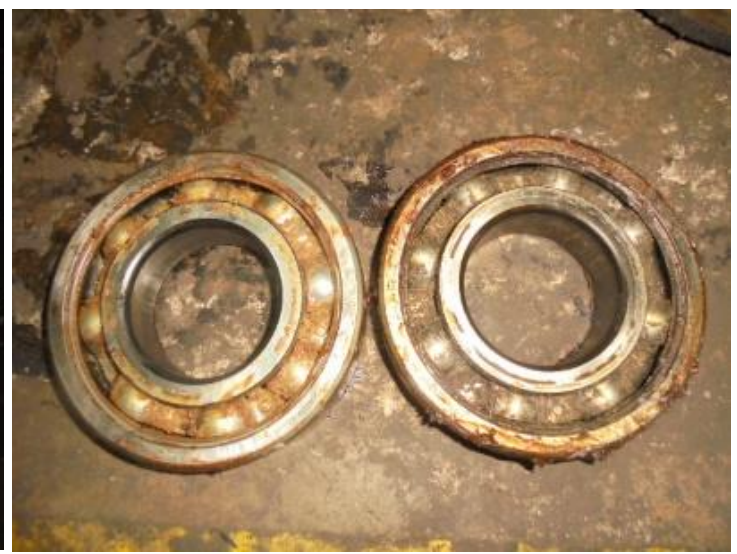

(b)
Table 3. Vibration measurement result of $55 \mathrm{~kW}$ motor

\begin{tabular}{|l|l|l|l|l|l|l|}
\hline \multirow{2}{*}{$\begin{array}{l}\text { Honi } \\
\text { zontal }\end{array}$} & \multicolumn{2}{|c|}{$\begin{array}{c}\text { 1xRPS } \\
(\mathbf{m m} / \mathbf{S})\end{array}$} & \multicolumn{2}{c|}{$\begin{array}{c}\text { 2xRPS } \\
(\mathbf{m m} / \mathbf{S})\end{array}$} & \multicolumn{2}{|c|}{$\begin{array}{c}\text { 3xRPS } \\
(\mathbf{m m} / \mathbf{S})\end{array}$} \\
\cline { 2 - 7 } & Before & After & Before & After & Before & After \\
\hline Front & 0.12 & 0.80 & 0.04 & 0.02 & 0.84 & 0.005 \\
\hline Rear & 0.11 & 0.27 & 0.04 & 0.03 & 0.46 & 0.015 \\
\hline
\end{tabular}

From Table 3, before maintenance, vibration values occur at frequencies: $1 x R P S, 2 x R P S$, and $3 x R P S$, indicating harmonic values and bearing looseness. After maintenance, values at the frequencies 2xRPS and 3xRPS is decreased, while the frequency $1 \times$ RPS is increased, indicating the rotor unbalance with a good level of vibration.

Table 4. Results of defects due to bearing faults of $55 \mathrm{~kW}$

\begin{tabular}{|l|c|c|}
\multicolumn{1}{c}{ Condition } & gE & Remarks \\
\hline Before maintenance & 1.920 & Good performance \\
After maintenance & 0.155 & less than $0.6 \mathrm{gE}$ \\
\hline
\end{tabular}

Figure. 14 of $55 \mathrm{~kW}$ motor before maintenance: (a) bearing housing and (b) bearing

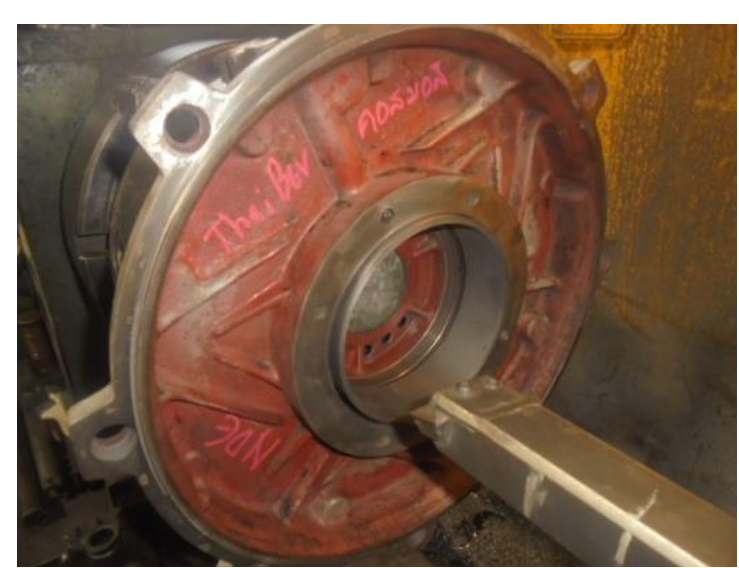

(a)

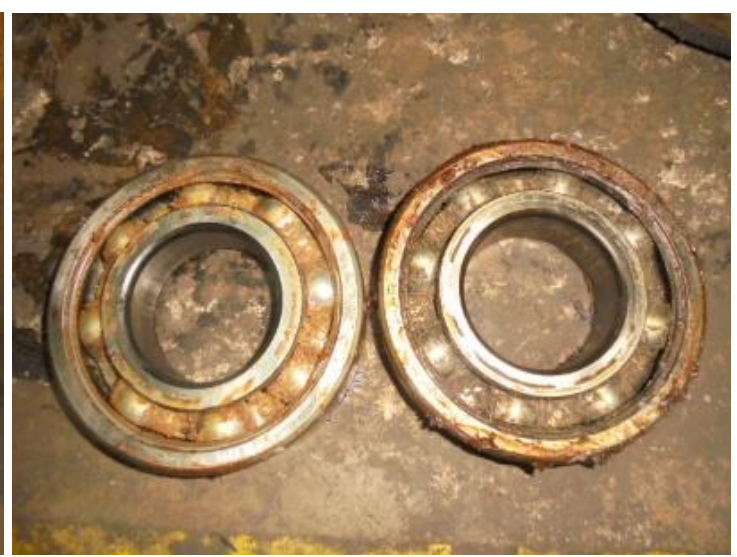

(b)

Figure. 15 Parts of 55kW motor after maintenance (a) bearing housing and (b) bearing 


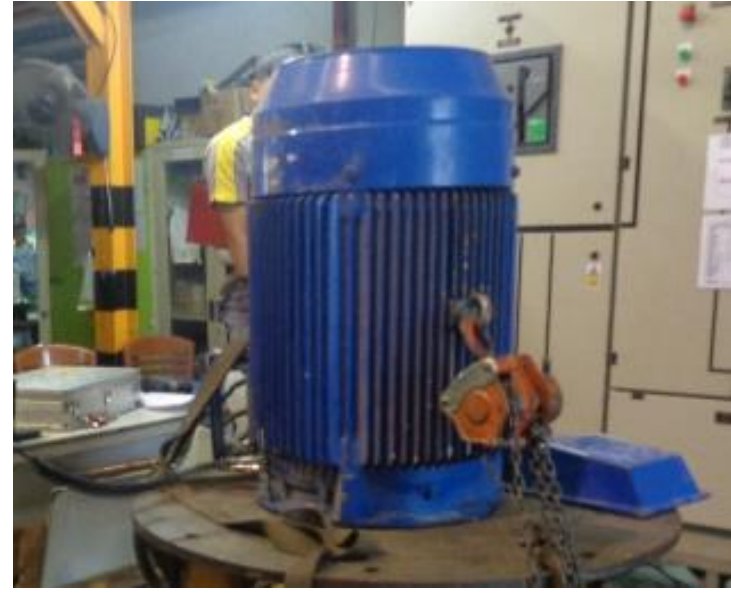

(a)

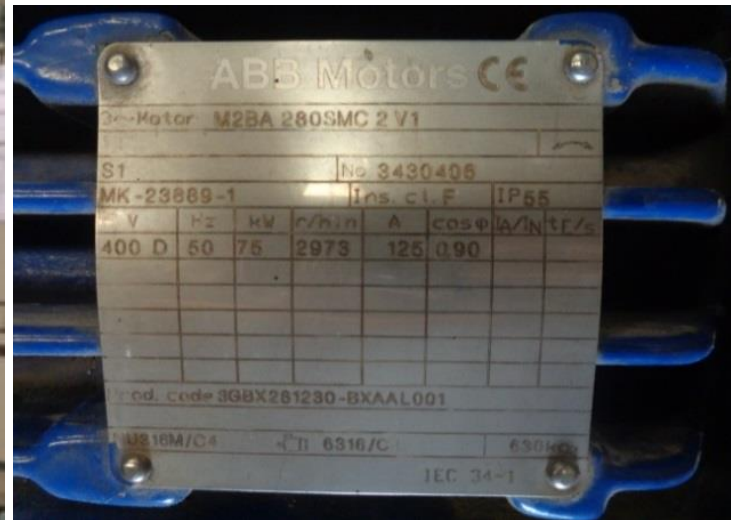

(b)

Figure. $1675 \mathrm{~kW}$ motor with 2,973 rpm in the experiment: (a) tested motor and (b) motor's nameplate

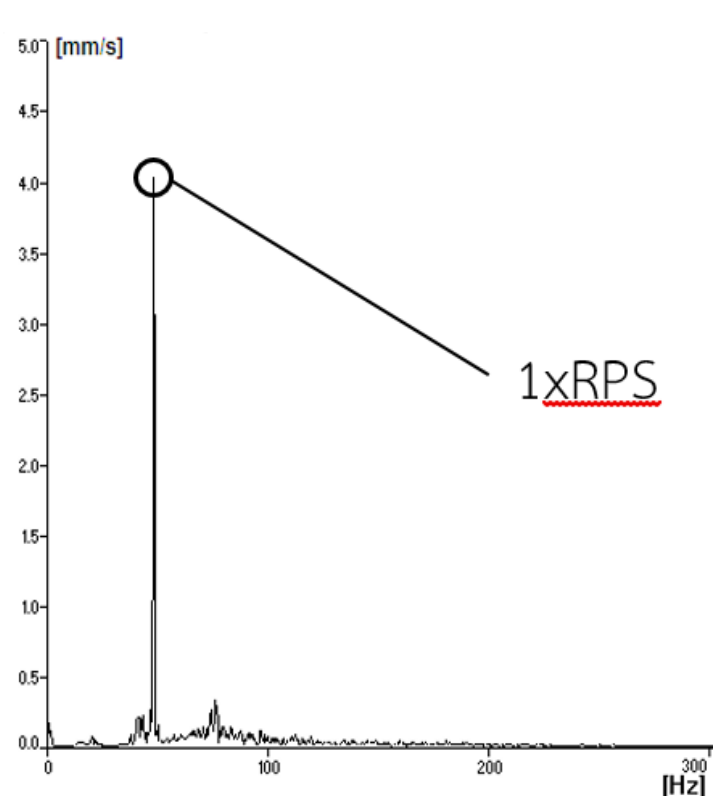

(a)

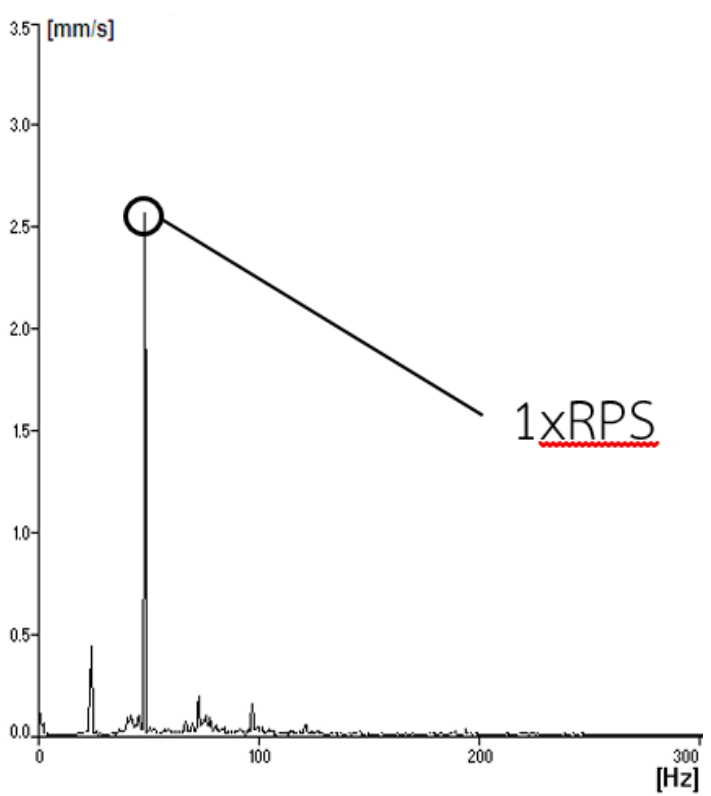

(b)

Figure. 17 Vibration results from $75 \mathrm{~kW}$ motor: (a) before maintenance and (b) after maintenance

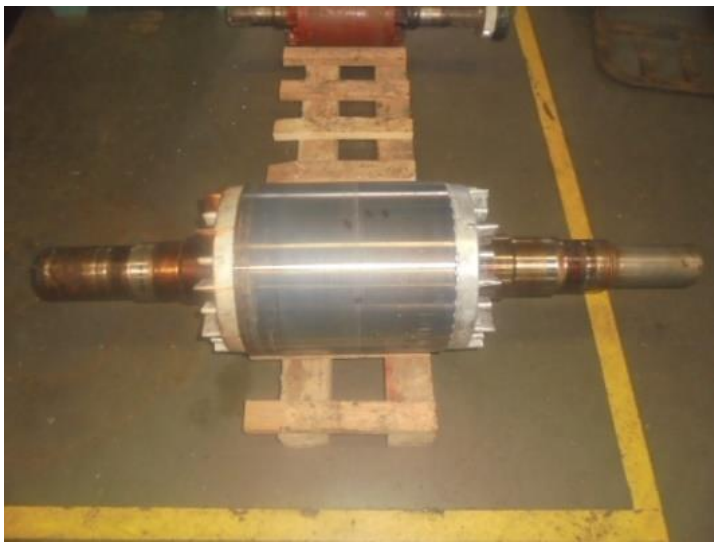

(a)

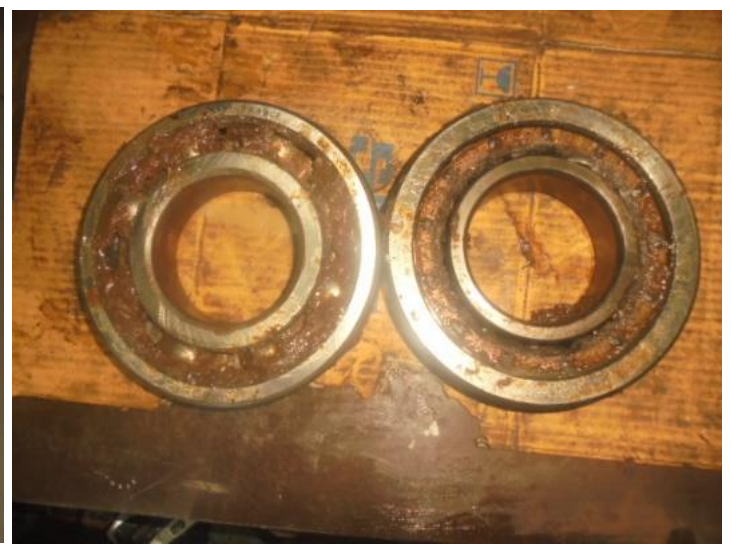

(b)

Figure. 18 Parts of $75 \mathrm{~kW}$ motor before maintenance: (a) rotor and (b) bearing 


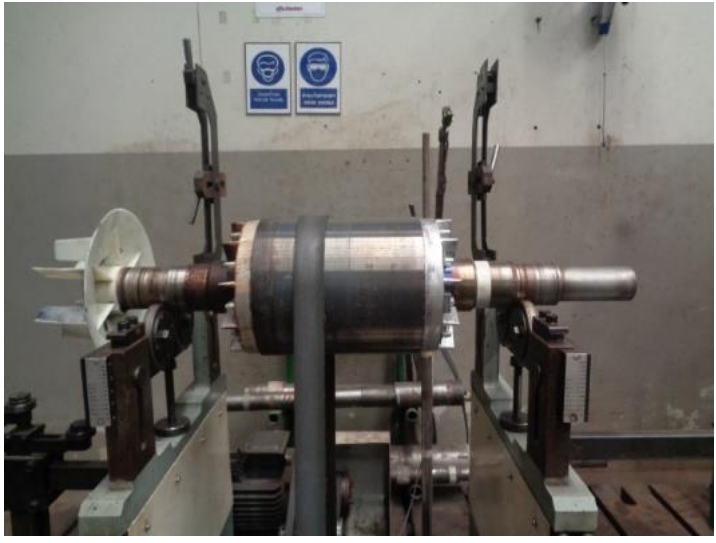

(a)

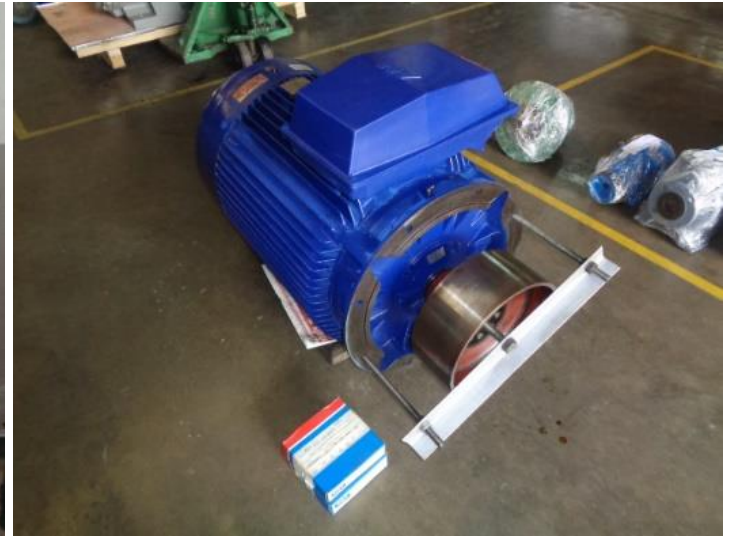

(b)

Figure. 19 Parts of $75 \mathrm{~kW}$ motor after maintenance: (a) rotor balancing and (b) motor

Table 5. Vibration measurement result of $75 \mathrm{~kW}$ motor

\begin{tabular}{|c|c|c|c|c|c|c|}
\hline \multirow{2}{*}{$\begin{array}{c}\text { Hori } \\
\text { zontal }\end{array}$} & \multicolumn{2}{|c|}{$\begin{array}{c}\text { 1xRPS } \\
(\mathbf{m m} / \mathbf{S})\end{array}$} & \multicolumn{2}{c|}{$\begin{array}{c}\text { 2xRPS } \\
(\mathbf{m m} / \mathbf{S})\end{array}$} & \multicolumn{2}{|c|}{$\begin{array}{c}\text { 3xRPS } \\
(\mathbf{m m} / \mathbf{S})\end{array}$} \\
\cline { 2 - 7 } & Before & After & Before & After & Before & After \\
\hline Front & 4.00 & 2.55 & 0.12 & 0.11 & 0.02 & 0.01 \\
\hline Rear & 2.72 & 2.25 & 0.06 & 0.02 & 0.05 & 0.01 \\
\hline
\end{tabular}

Table 6. Results of defects due to bearing faults of $75 \mathrm{~kW}$

\begin{tabular}{|l|c|l|}
\hline \multicolumn{1}{|c|}{ Condition } & gE & Remarks \\
\hline Before maintenance & 1.980 & Good performance \\
\cline { 1 - 2 } After maintenance & 0.169 & less than $1.3 \mathrm{gE}$ \\
\hline
\end{tabular}

From Table 4, before maintenance, the gE value was at 1.92 , representing the defects caused by the bearing. After replacing the bearing, the gE value was decreased.

3) Results of the experiment on the $75 \mathrm{~kW}$ motor with 2,973 rpm as shown in Figs. 16-19 and Tables 5-6.

From Table 5, before maintenance, the vibration value at the frequency 1 xRPS was rather high when compared to other frequencies, indicating the rotor unbalance as shown in Fig. 4. After correcting, the value at the frequency $1 \times$ RPS was decreased.

From Table 6, before maintenance, the gE value was at 1.980 , representing the defects caused by the bearing. After replacing the bearing, the $\mathrm{gE}$ value was decreased.

\section{Analysis results}

The efficiency analysis of the electric motor using vibration measurement is based on the ISO 10816-3 standard to determine overall efficiency of the motor as shown in Fig. 6. Causes of damage from housing bearing loosening and the rotor unbalanced are shown in Fig. 4. The classification of bearing fault levels is based on the principle of Acceleration Enveloping $) g E$ ( as shown in Fig. 3.

From Fig. 6, all 3 experiment motors are classified as flexible-type Group 2 and the vibration value less than $4.5 \mathrm{~mm} / \mathrm{s}$ represents the acceptable performance.

By considering the motor defects are caused by the housing bearing looseness, the frequencies cover from 1xRPS, 2xRPS to 10xRPS, Results of the experiment on the $22 \mathrm{~kW}$ motor and $55 \mathrm{~kW}$. Before maintenance, vibration values occur at frequencies: 1xRPS, 2xRPS, and 3xRPS, indicating harmonic values and bearing looseness. After maintenance, the values at the frequencies $2 \times R P S$ and $3 \times R P S$ is decreased.

By considering the motor defects caused by the rotor unbalance covers the frequency at 1xRPM. Results of the experiment on the $75 \mathrm{~kW}$ show that before maintenance, the vibration value at the frequency 1xRPS was rather high when compared to other frequencies, indicating the rotor unbalance. After correcting, the value at the frequency 1xRPS was decreased.

From Fig. 3, the gE values indicating the effective performance of bearings are considered by the RPM of specified motors. All 3 experiment motors. Before maintenance, the measured $\mathrm{gE}$, representing the defects caused by the bearing. After replacing the bearing, the $\mathrm{gE}$ value was decreased.

\section{Conclusion}

The analysis result from all those 3 sized of tested motors recommends that in order to maintain motors in normal operation condition, the vibration measuring result should be kept within the recommended value in Fig. 6. Moreover, the gE value should be maintain within limit shown in Fig. 3. In addition, the recommended value of vibration at 1xRPS frequency should be kept lower than number in Fig. 6 which indicate that fault come from rotor 
imbalance. However, at the frequency 2xRPS and $3 x R P S$, it should not have vibration show up which imply that the bearing looseness have occurred.

From the test to measure the vibrations and the $\mathrm{gE}$ of all three electric motors at different frequencies, it can be used to diagnose and analysis the efficiency of electric motors for future maintenance plans.

From three experiments, the results obtained from the vibration measurement at different frequencies will be used for further diagnosis and analysis of electric motors.

\section{Conflicts of Interest}

The authors declare no conflict of interest.

\section{Author Contributions}

In this research papers, individual authors have their contributions and responsibility as following: conceptualization and methodology, B. Suechoey, S. Siriporananon, P. Chupun and C. Chompooinwai; data validation/curation, S. Siriporananon and P. Chupun; result analysis and conclusion, B. Suechoey, S. Siriporananon, P. Chupun and C. Chompooinwai; writing, original draft preparation, review and editing, B. Suechoey, C. Bonkhun and C. Chompooinwai.

\section{Acknowledgments}

The authors would like to thank Chupun Industrial Services Co., Ltd. with great appreciation for valuable supports the electric motor, equipement and tools used in this research.

\section{References}

[1] IEEE Motor Reliability Working Group, "Report of large motor reliability survey of industrial commercial installation", Part 1, IEEE Trans. Ind. Applicat., Vol .IA-21, pp.853872, 1985.

[2] D. Kowal, "Proactive Maintenance Strategy for Electrically Induced Bearing Damage", Computational Systems, Inc., pp. 25-38, 2018.

[3] J. C. Berggren, "Diagnosing Faults in Rolling Element Bearings", Part 1, Assessing Bearing Condition; Vibrations, Vol. 4, No. 1, pp. 1-5, 1988.

[4] J. Jung, S. B. Lee, C. Lim, C. Cho, K. Kim, "Electrical Monitoring of Mechanical Looseness for Induction Motors with Sleeve Bearings", IEEE Transactions on Energy Conversion, Vol. 31, pp. 1377-1386, 2016.

[5] R. Kilic, "Determination of Imbalance Problem in Electric Motor and Centrifugal Pump by Vibration Analysis", In: Proc. of Special Issue of the 2nd International Conf. on Computational and Experimental Science and Engineering )ICCESEN 2015(, Vol. 130, No. 1, pp. 487-491, 2015.

[6] P. C. Latane and P. C. Urolgin, "Fault Detection in Electric Motors Using Vibration Analysis and DSP Processor", International Journal of Innovative Research in Science, Engineering and Technology, Vol. 5, pp. 11590-11597, 2016.

[7] M. Sonowal, B. B. Gogoi, M. Boruah, and J. K. Barman, "Health Monitoring of Induction Motor through Vibration Analysis", ADBU Journal of Electrical and Electronics Engineering )AJEEE(, Vol. 3, pp. 1-8, 2019.

[8] L. Clupitu, D. Turcan, A. Tudor, and D. Sandor, "Vibration Diagnosis of Electric Motor's Bearings", Advanced Materials Research, Trans Tech Publication, Switzerland, Vol. 463-464, pp. 1725-1728, 2012.

[9] SKF USA Inc., "Bearing Conditions Value", https://www.skf.com/cm.

[10] Technical Associates of Charlotte, Inc. "Illustrat ed Vibration Diagnostic Chart", https://www.artec-machine.com/wpcontent/docs/protected/illustrated_vibration_dia gnostic_chart.pdf

[11] BS ISO 10816-3:2009+A1:2017 "Mechanical vibration. Evaluation of machine vibration by measurements on non-rotating parts Industrial machines with nominal power above $15 \mathrm{~kW}$ and nominal speeds between $120 \mathrm{r} / \mathrm{min}$ and 15000 $\mathrm{r} / \mathrm{min}$ when measured in situ", pp. 10-22, 2017.

[12] P. V. J. Rodríguez, "Current-, Force-, and Vibration-Based Techniques for Induction Motor Condition Monitoring", Dissertation for the degree of Doctor of Science in Technology. University of Technology, Espoo, pp. 15-33 2007.

[13] P. Chupun, B. Suechoey, and S. Siriporananon, "Performance Analysis of Electric Motors Using Vibration Measurement", In: Proc. of International Conf. on Power, Energy and Innovation (ICPEI 2019), Pattaya, Thailand, pp. 1-4, 2019.

[14] P. Chupun, B. Suechoey, and S. Siriporananon, "Electrical Performance Testing of AC Motors", In: Proc. of International Conf. on Power, Energy and Innovation (ICPEI 2019), Pattaya, Thailand, pp. 1-3, 2019.

[15] B. Suechoey, J. Boonseng, C. Chompooinwai, and C. Chompooinwai, "Analysis of Winding Temperature and Design of Distribution Transformer for Improving Short Circuit Withstand Capability under Renewable Generations Mixed Environment", International 
Received: July 14, 2020. Revised: October 15, 2020.

Journal of Intelligent Engineering and Systems, Vol. 11, No. 6, pp. $11-20,2018$. 